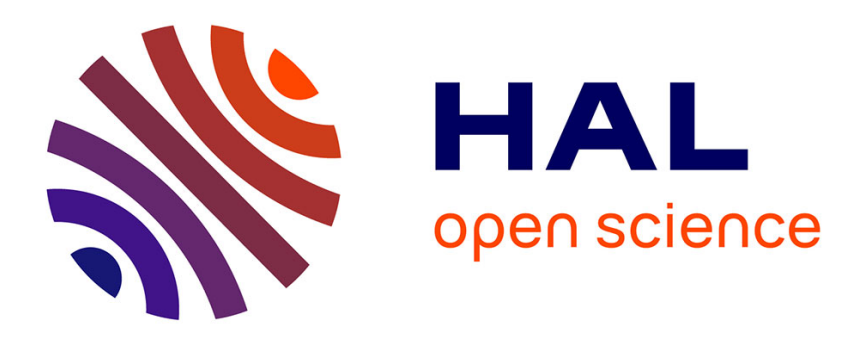

\title{
Optical and electro-optical behaviour of a liquid crystal helicoidal structure
}

F. Gharadjedaghi, J. Robert

\section{To cite this version:}

F. Gharadjedaghi, J. Robert. Optical and electro-optical behaviour of a liquid crystal helicoidal structure. Revue de Physique Appliquée, 1975, 10 (2), pp.69-73. 10.1051/rphysap:0197500100206900 . jpa-00243882

\section{HAL Id: jpa-00243882 https://hal.science/jpa-00243882}

Submitted on 1 Jan 1975

HAL is a multi-disciplinary open access archive for the deposit and dissemination of scientific research documents, whether they are published or not. The documents may come from teaching and research institutions in France or abroad, or from public or private research centers.
L'archive ouverte pluridisciplinaire HAL, est destinée au dépôt et à la diffusion de documents scientifiques de niveau recherche, publiés ou non, émanant des établissements d'enseignement et de recherche français ou étrangers, des laboratoires publics ou privés. 


\title{
OPTICAL AND ELECTRO-OPTICAL BEHAVIOUR OF A LIQUID CRYSTAL HELICOIDAL STRUCTURE (*)
}

\author{
F. GHARADJEDAGHI and J. ROBERT
}

\author{
C. E. N. G.-L. E. T. I., BP 85, Centre de Tri, 38041 Grenoble Cedex, France
}

(Reçu le 22 juillet 1974, révisé le 18 septembre 1974)

\begin{abstract}
Résumé. - Les propriétés optiques et électro-optiques des structures nématiques en hélice ou cholestériques sont très voisines. Nous avons étudié la nature de l'onde optique à la sortie d'un tel milieu, lorsque la direction de polarisation de la lumière incidente est parallèle aux premières molécules rencontrées. Nous présentons des résultats relatifs à leur comportement électro-optique dans les deux cas suivants : le champ électrique est parallèle ou perpendiculaire à la direction des molécules au repos. (L'anisotropie diélectrique des molécules est positive.)

Abstract. - Optical and electro-optical properties of twisted nematic or cholesteric structures are very similar. For these structures the nature of the output optical wave is given when the incident light polarization is parallel to the first encountered molecules. The electro-optical behaviour is studied in the two following cases : the electric field is parallel or perpendicular to the molecules at rest. (The dielectric anisotropy of molecules is positive.)
\end{abstract}

1. Introduction. - The liquid crystal helicoidal structures present particular optical and electrooptical properties, and are interesting in more and more applications. Among these, there are alpha numeric displays, matrix addressing displays, electro-optical modulator, analog deflectors and so on...

The helicoidal structures studied in this paper are planar structures in which the total rotation of the molecules in the cell is $\varphi_{0}$.

The liquid crystals used can be cholesterics or nematics twisted by surface alignment stresses.

The first part of this paper is related to the optical properties and the second to the electro-optical behaviour.

2. Optical properties of the planar twisted structures. - In a planar structure, the helix axis is perpendicular to the glass plates and parallel to the light beam. The medium is characterized by the birefringence $\Delta n=n_{\mathrm{e}}-n_{0}$, by the thickness of the cell : $L$ and by the twist angle $\varphi_{0}$.

When the incident polarization direction is parallel to the first encountered molecules, the mathematical formulas (1), (2) giving the rotation of the polarization plane $\delta$ and the ellipticity $e$ of the output optical waves are :

$$
\begin{array}{r}
\delta=\varphi_{0}-\frac{1}{2} \tan ^{-1} \frac{\varphi_{0} \sqrt{\alpha_{0}^{2}+\varphi_{0}^{2}} \sin 2 \sqrt{\alpha_{0}^{2}+\varphi_{0}^{2}}}{\alpha_{0}^{2}+\varphi_{0}^{2} \cos 2 \sqrt{\alpha_{0}^{2}+\varphi_{0}^{2}}} \\
e=\tan \left[\frac{1}{2} \sin ^{-1}\left(\frac{2 \alpha_{0} \varphi_{0}}{\alpha_{0}^{2}+\varphi_{0}^{2}} \sin ^{2} \sqrt{\alpha_{0}^{2}+\varphi_{0}^{2}}\right)\right]
\end{array}
$$

(*) Paper presented at the Vth Int. Liquid Crystal Conf., June 17-21, 1974, Stockholm, Sweden. where $\varphi_{0}$ is the twist angle of the structure; $\alpha_{0}=\pi(\Delta n L) / \lambda:$ Optical parameter of the medium $; \lambda$ is the wavelength of the light.

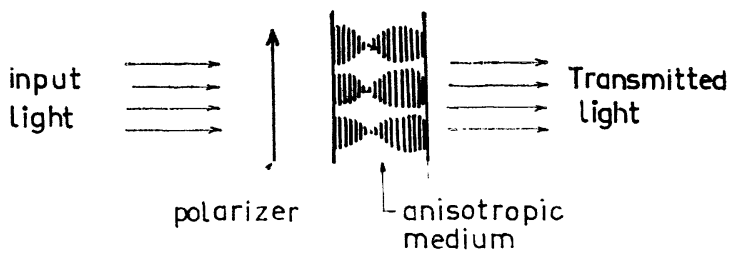

FIG. 1. - Schematic diagram of the molecular organization.

In the particular case where the output wave is analysed by a polarizer parallel to the incident one, the intensity of the transmitted light is given by :

$$
\begin{aligned}
I=\left(\cos \varphi_{0} \cos \sqrt{\alpha_{0}^{2}+\varphi_{0}^{2}}+\right. \\
\left.+\frac{\varphi_{0}}{\sqrt{\alpha_{0}^{2}+\varphi_{0}^{2}}} \sin \varphi_{0} \sin \sqrt{\alpha_{0}^{2}+\varphi_{0}^{2}}\right)^{2} \\
+\frac{\alpha_{0}^{2}}{\alpha_{0}^{2}+\varphi_{0}^{2}} \cos ^{2} \varphi_{0} \sin ^{2} \sqrt{\alpha_{0}^{2}+\varphi_{0}^{2}}
\end{aligned}
$$

The curves giving $\delta, e$ and $I$ versus the parameter $\Delta n L / \lambda$ are plotted on figures 2,3 and 4 .

The calculations show that particular curves are obtained when

$$
\varphi_{0}=\frac{\pi}{2 \sqrt{2}}(2 k+1)
$$




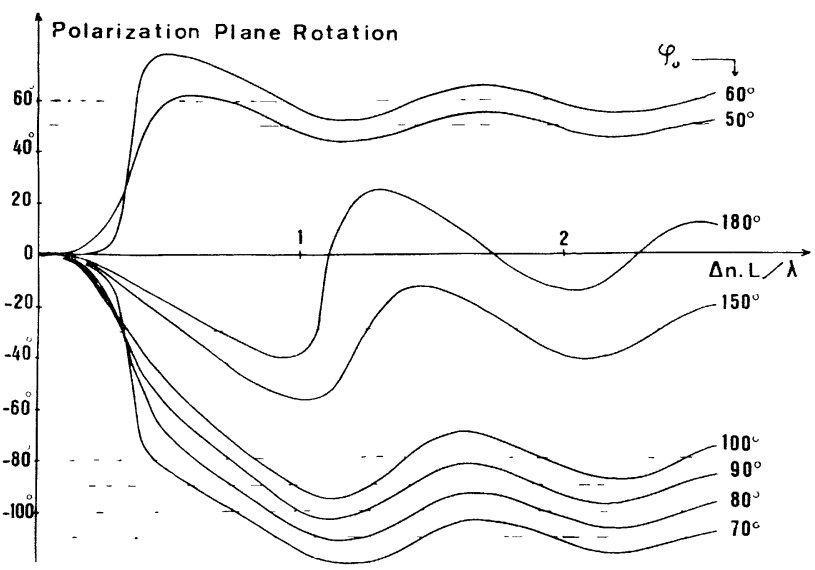

FIG. 2. - Polarization plane rotation versus $\Delta n L / \lambda$ for different values of the twist angle $\varphi_{0}$.

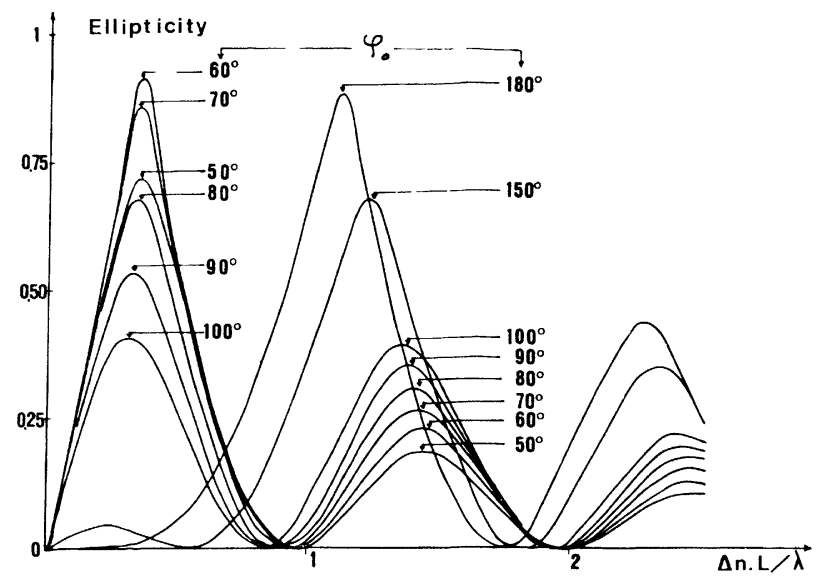

FIG. 3. - Ellipticity versus $\Delta n L / \lambda$ for different values of the twist angle $\varphi_{0}$.

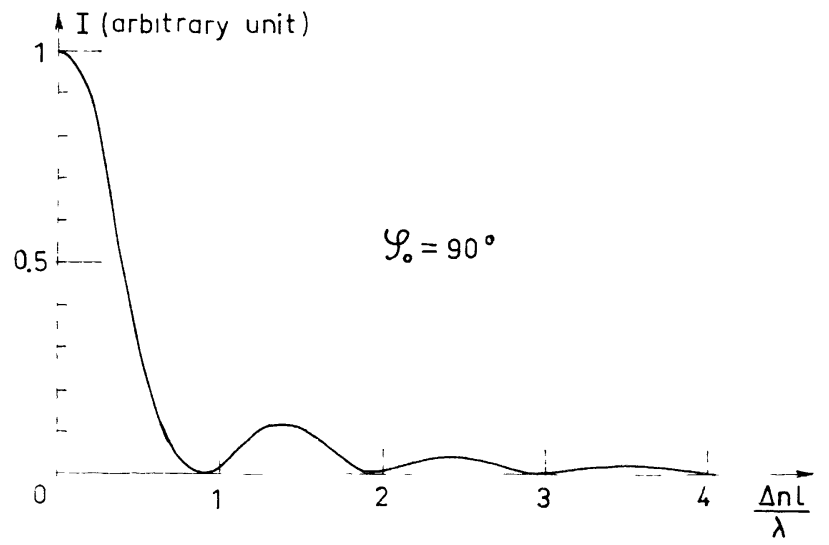

FIG. 4. - Transmitted intensity versus $\Delta n L / \lambda$ between parallel polarizers for $\varphi_{0}=90^{\circ}$.

( $k$ being an integer) and discontinuities occur in the curve $\delta(\Delta n L / \lambda)$ for

$$
\Delta n L / \lambda=\frac{2 k+1}{2 \sqrt{2}}
$$

For

$$
\varphi_{0}=\frac{\pi(2 k+1)}{2 \sqrt{2}} \text { and } \frac{\Delta n L}{\lambda}=\frac{2 k+1}{2 \sqrt{2}}
$$

the ellipticity is equal to 1 , consequently, the output wave is circularly polarized.

Such curves are drawn on figure 5 around the particular value of $\varphi_{0}$ equal to $3 \pi / 2 \sqrt{2}$ or 190.92 degrees and experimental verifications were made.

So, on the same cell, two different twist angles, of 180 and 270 degrees are induced.

The molecular orientation on the glass plates is controlled by the well known Silicon Oxide coating [3].

The orientation on the first glass plate is uniform

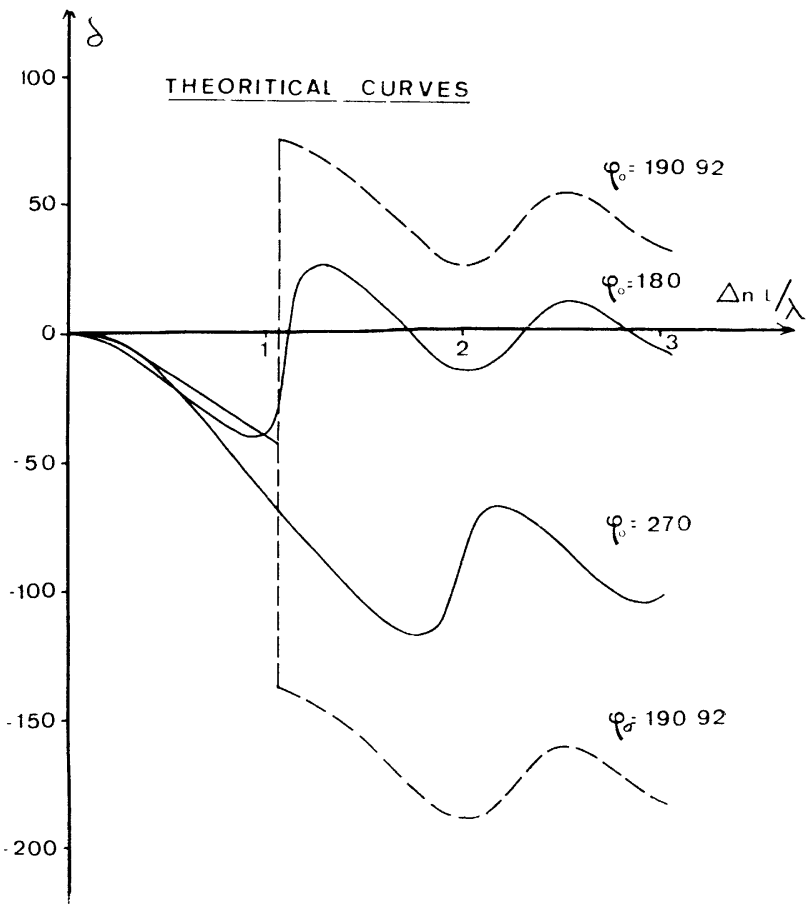

(a)

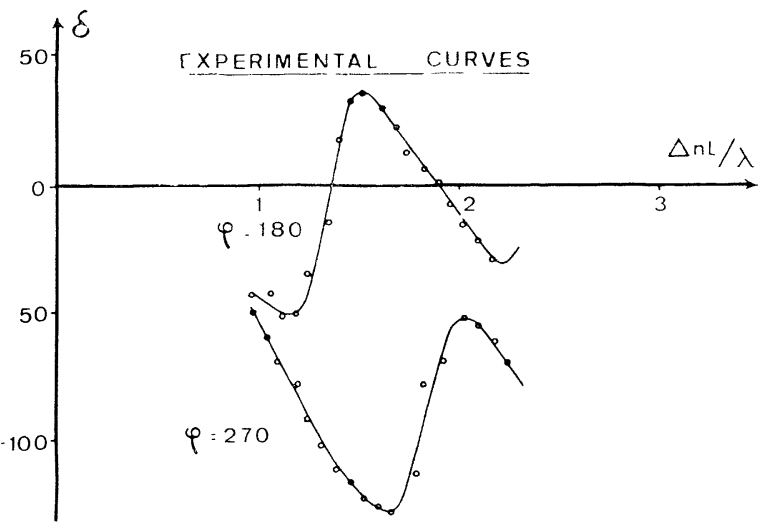

(b)

FIG. 5. - On the left : theoretical curves $\delta(\Delta n L / \lambda)$ for $\varphi_{0}=180^{\circ}$, $270^{\circ}$ and the critical value : $190.92^{\circ}$. On the right : experimental curves $\delta(\Delta n L / \lambda)$ for $\varphi_{0}=180^{\circ}$ and $270^{\circ}$. 

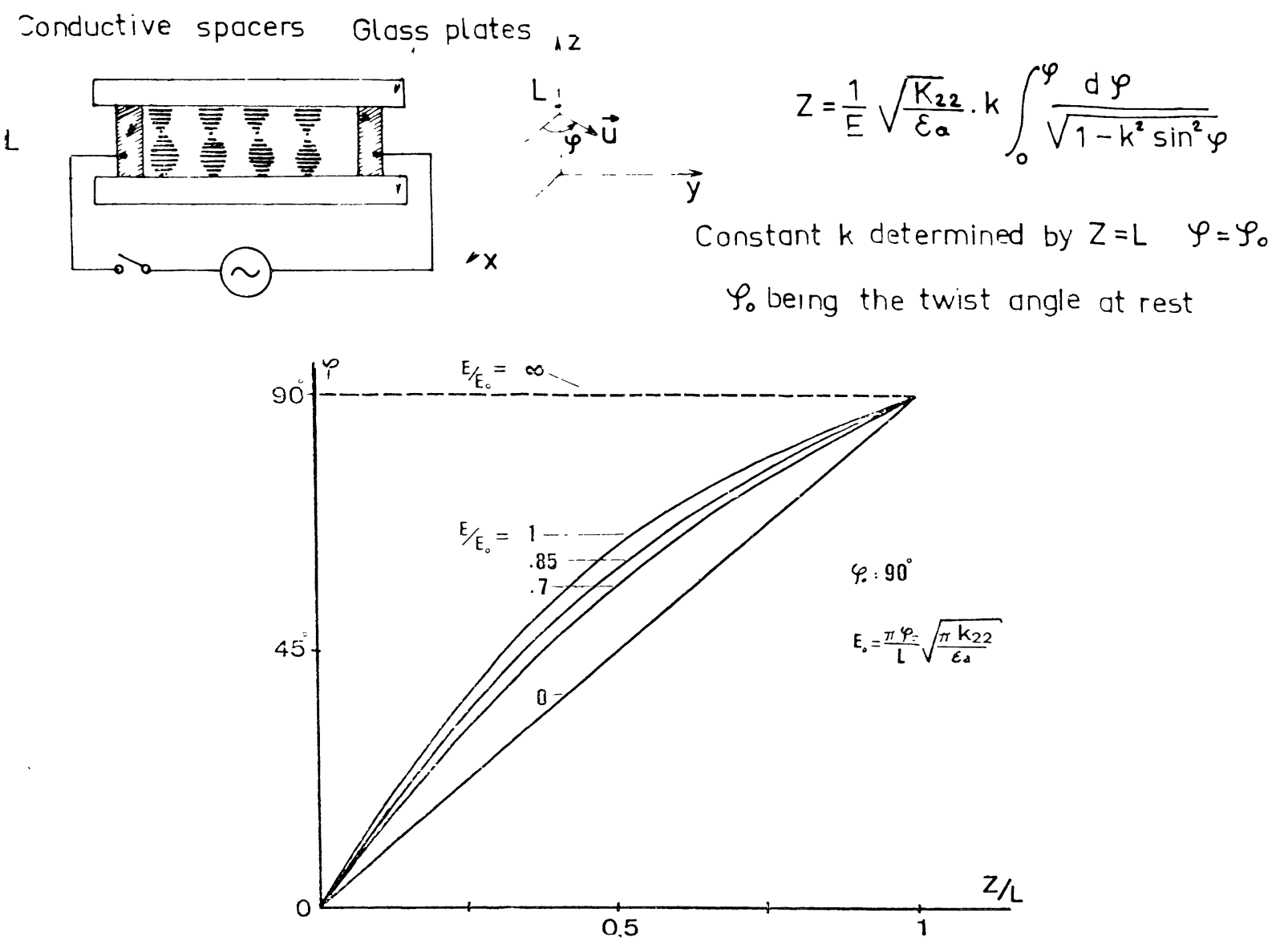

Fig. 6. - Molecule angular distortion of a bounded cholesteric medium by electric field.

and the second glass plate is divided in two areas with perpendicular orientations.

The thickness of the cell is approximatively $3.5 \mu \mathrm{m}$.

The liquid crystal used is a mixture of MBBA and C. O. C. with a $2 \mu \mathrm{m}$ pitch.

Thus, in the same cell, two helicoidal structures with different twist angles are induced. The experimental variable is the light wavelength $\lambda$. The polarization plane rotations are plotted, in both cases, versus $\Delta n L / \lambda$ ( $\Delta n$ is also dependent on $\lambda$ ). The experimental results given in figure 5 are in good agreement with the theoretical data although the oscillations amplitude are larger than the theoretical ones. This fact is probably due to the distortions of the helicoidal structures induced by the mechanical stresses of the walls because the thickness of the cell is not equal to $k p_{0}$ ( $p_{0}$ is the natural pitch and $k$ is an integer)

3. Electric field dependence on the optical properties. - 3.1 LONGITUdinal ELECTRIC FIELD. - The applied electric field is parallel to the molecules at rest, and the dielectric anisotropy of molecules is positive $\left(\varepsilon_{\|}>\varepsilon_{\perp}\right)$.

The cell is made of two glass plates. Upon one, parallel aluminium strips of 7 to $10 \mu \mathrm{m}$ thick are deposited. These serve as spacers and electrodes. The two plates are covered with a Silicon oxide oblique deposit to insure the suitable orientation of molecules.
We computed the distortion of this bound helicoidal structure. The results are summed up on figure 6 .

The transmitted optical intensity between parallel polarizers for $\varphi_{0}=90^{\circ}$ is computed versus $\Delta n L / \lambda$ for different values of the reduced parameter $E / E_{0}$ and plotted on figure 7 .

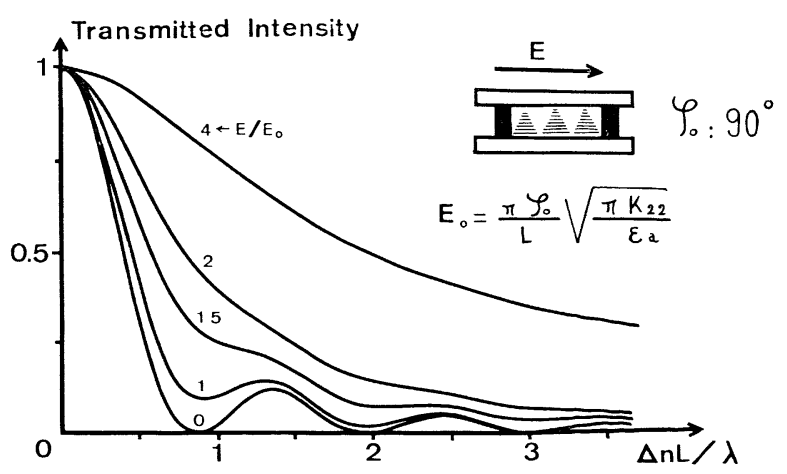

FIG. 7. - Longitudinal electric field : transmitted intensity versus $\Delta n L / \lambda$ between parallel polarizers for different values of the parameter $E / E_{0}$ and for $\varphi_{0}=90^{\circ}$.

Measurements of the polarization plane rotation versus the intensity of the a. c. applied electric field show the unwinding of the structure and permit detec- 
tion of the presence of two opposite twist areas in the cell (Fig. 8). This electro-optical effect does not present a threshold ; the calculations and the experiments bear out this result.

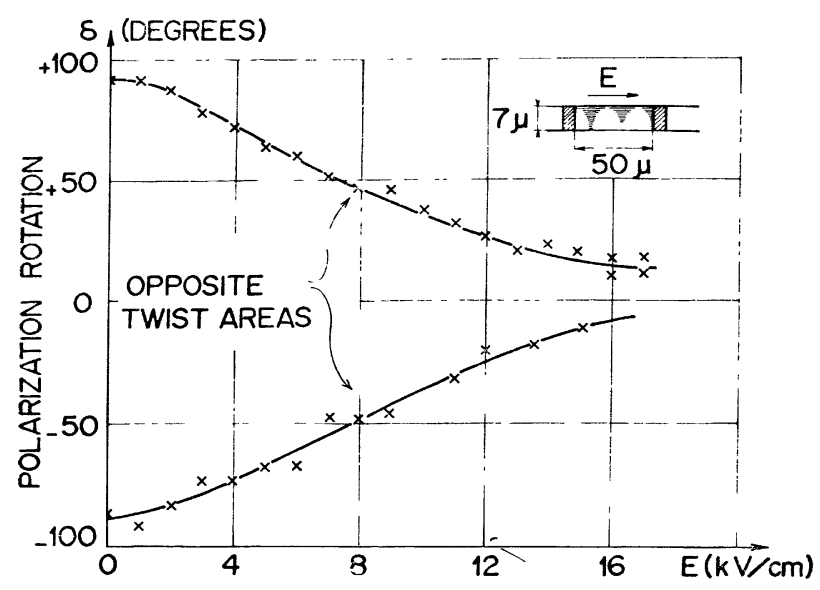

FIG. 8. - Longitudinal electric field : rotation of the polarization plane (experimental date) versus electric field amplitude $E$ and for $\varphi_{0}=90^{\circ}$.

3.2 Transverse Electric Field. - The applied electric field is now perpendicular to the molecules at rest. It is the well known configuration.

Theoretical computations of the structure distortion by electric field were published by Berreman [4], so, we will give only our observations and experimental results.

The experimental cell is made of two glass plates coated with indium oxide and Silicon oxide oblique deposit. The twist angle is $90^{\circ}$ and the liquid crystal used is A. B. A. B. N. (Schiff base mixture with cyano group).

The rotation of the output polarization plane of the cell versus the applied voltage as the optical transmitted intensity between crossed polarizers are drawn on figure 9. These two curves show oscillations before the

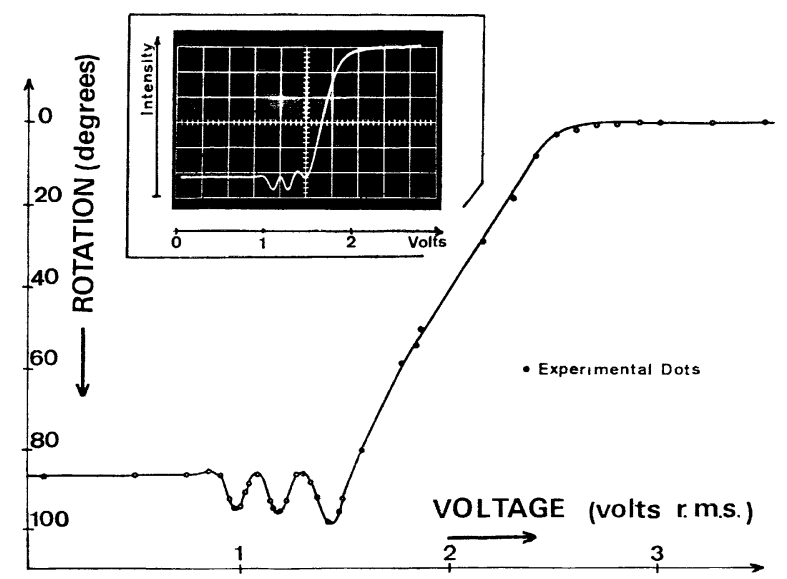

FIG. 9. - Transverse electric field : rotation of the polarization plane and intensity between parallel polarizers versus the applied voltage $V$ for $\varphi_{0}=90^{\circ}$. complete unwinding of the helicoidal structure. Just above the Freederick's threshold, the twisted structure exists, but the molecules are slightly tilted (the twisted smectic $\mathrm{C}$ presents an equivalent structure). The molecules begin to tilt in a plane perpendicular to the plates as Berreman's computations show. So, the induced birefringence $\Delta n$ decreases, and the rotation of the polarization plane and the transmitted intensity oscillate according to the theoretical curves in figure 3 in the former case and in figure 4 in the latter case. Thus, fine measurements of either the polarization plane rotation or the transmitted intensity versus applied voltage give a way for the determination of the Freederick's transition threshold voltage.

The dynamic optical behaviour of a twisted nematic cell is peculiar. The decay time presents generally a bounce that is sometimes attributed to a back flow effect [5]. Obviously, this last effect exists [6], [7] but must not induce an important optical effect. If the back flow effect is important in a homeotropic structure the van Doorn's computations prove that its optical effect is negligible in the twisted structure. Indeed, the maximum computed value of the molecule oscillation rotation in the middle of the cell is $93^{\circ}$ when $E / E_{\mathrm{c}}=4$. Thus, the induced birefringence is lower than 0.0005 and the optical intensity variation does not exceed $0.4 \%$ (20 $\mu \mathrm{m}$ for the cell thickness). Experimentally, the first minimum is at $I / 2$.

On the other hand, measurement of the cell capacity variation is the reflection of the tilt molecular angle variation and does not show an anomalous behaviour
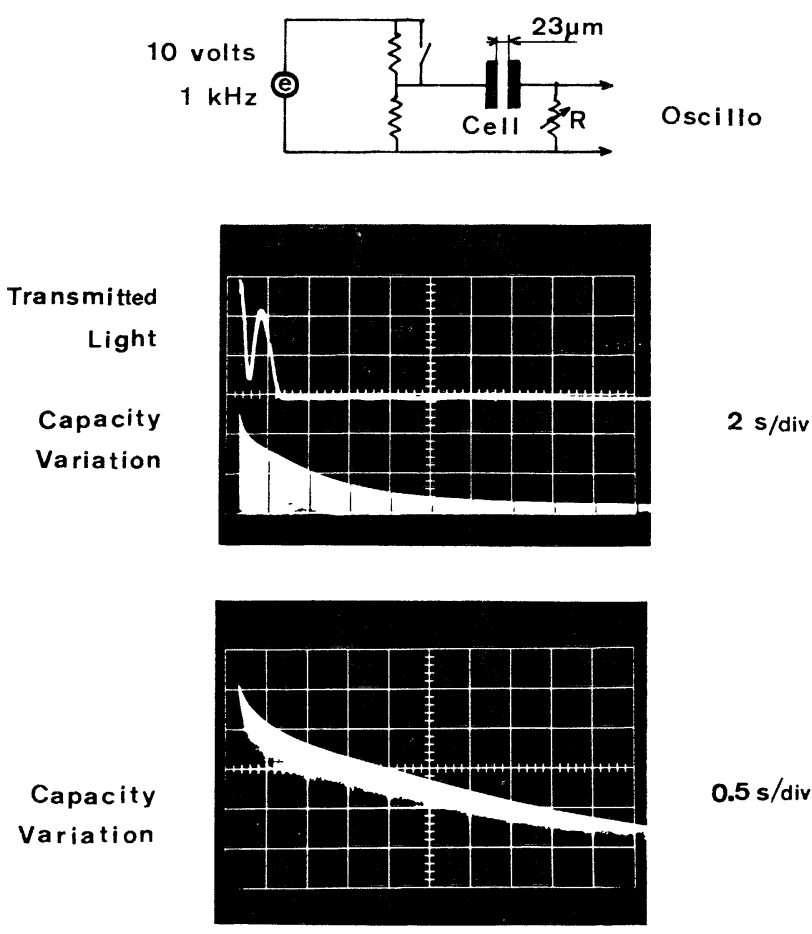

FIG. 10. - Transverse electric field: dynamic behaviour : a) Capacitance measurement set up ; $b$ ) Optical and capacitance variation versus time; $c$ ) Capacitance variation versus time (expanded seanning). 
during the decay time. Therefore, the oscillation amplitude has to be small. The capacity variation versus time for the electrical measurement circuit are given on figure 10.

We think this bounce is due to a polarimetric effect i. e. to a coupled effect of the rotation of the polarization plane and the ellipticity of the output wave. The transmitted optical intensity due to this polarimetric effect during the bounce time is increased by an important distortion of the structure.

\section{References}

[1] Robert, J. and Gharadjedaghi, F., C. R. Hebd. Séan. Acad. Sci. 278B (1974) 73.

[2] Gharadjedaghi, F. and Robert, J., Electron. Lett. (submitted).

[3] Janning, J. L., Appl. Phys. Lett. 21 (1972) 173 ;

Guyon, E., Pieranski, P., Boix, M., to be published in Letters in Applied and Engineering Science.
[4] Berreman, D. W., J. Opt. Soc. Am. 63 (1973) 1374 and J. Appl. Phys. 25 (1974) 12.

[5] Van Doorn, C. Z., to be published in Phys. Lett. and Vth Liquid Crystal Conference, Stockholm June, 74.

[6] Brochard, F., Pieranski, P., Guyon, E., Phys. Rev. Lett. 28 (1972) 1681.

[7] Brochard, F., J. Physique 33 (1972) 607. 